\title{
Democracia y empatía. El espacio que la habita, su progresión colectiva
}

\section{Democracy and empathy. The space that inhabits it, its collective progression}

\author{
Arq. Natasha Amelia Abad Betances \\ Máster en Diseño Arquitectónico, especialidad Diseño de Interiores \\ Universidad de la Coruña, España \\ abadbetances.n@gmail.com — https://orcid.org/0000-0003-2513-8455
}

Fecha de recepción: 28 de octubre de 2020

Fecha de aceptación: 16 de noviembre de 2020

Fecha de publicación: 1 de enero de 2021

Favor citar este artículo de la siguiente forma:

Abad Betances, N. (2021). Democracia y empatía. El espacio que la habita, su progresión colectiva.

AULA, Revista de Humanidades y Ciencias Sociales. 67 (1), 17-22

https://doi.org/10.33413/aulahcs.2021.67i1.147

\section{RESUMEN}

La discusión filosófica que engloba la democracia del siglo XXI abarca un significado colectivo más profundo de lo que la palabra refiere en su definición singular. La democracia es una doctrina / sistema político / forma de gobierno popular donde el pueblo elige. Y es en la elección donde se generan vertientes de aproximación a una idea que intenta ser colectiva.

Este artículo usa el sentimiento de la empatía como rasgo unificador entre la democracia y su búsqueda ante la sensibilización colectiva. En su definición, la empatía es un sentimiento de solidaridad hacia una persona o grupo (RAE, 2019). La empatía observa las relaciones del ser humano, se vincula en comunidades, invierte en generar ciudad para el bien común y es parte inconsciente del desarrollo de la civilización (Rifkin J. 2010). Otro concepto importante a destacar es el espacio en el que se genera el desarrollo situacional o in-situ. El espacio delimita el territorio y en él convergen la historia, su cultura y el tiempo unido a las sensaciones. El espacio adquiere condiciones en función a necesidades, se manifiesta como resultado de éstas (Rifkin J. 2010) y permite, como producto de la experiencia, reconocer el lugar donde el desarrollo colectivo toma acciones. En este artículo el espacio y el lugar van de la mano, siendo el compromiso que delimita la experiencia en términos geográficos.

Los siguientes párrafos tienen como objetivo recorrer el camino de ida (Piglia G. 2015) hacia la comprensión de la democracia en un siglo donde los valores humanos buscan igualarse con una trascendencia espiritual, y donde los sentimientos son emociones activas que juegan en la colectividad. Espacios donde se pueden reconocer cuestionamientos propios y ajenos dentro de un espectro posible; donde son escuchadas ambas partes, diseminadas sin apropiación y vinculadas como opciones. ¿Será posible reconocer la verdad del otro como propia? ¿Puede el ciudadano del siglo XXI observar valores fundamentales como la solidaridad, honestidad y la escucha, y definirlas como acciones progresivas para el desarrollo de la sociedad?

Palabras clave: ciudadano, democracia, empatía, espacio, solidaridad, valores. 


\begin{abstract}
The philosophical discussion that encompasses the democracy of the 21 st century encompasses a deeper collective meaning than what the word refers to in its singular definition. Democracy is a popular doctrine / political system / form of government where the people choose. And it is in the election where approaches to an idea that tries to be collective are generated.

This article uses the feeling of empathy as a unifying feature between democracy and its search for collective awareness. In its definition, empathy is a feeling of solidarity towards a person or group (Rae, 2019). Empathy observes the relationships of the human being, is linked in communities, invests in generating the city for the common good and is an unconscious part of the development of civilization (Rifkin J. 2010). Another important concept to highlight is the space, in which the situational or in-situ development is generated. The space delimits the territory and in it the history, its culture and the time together with the sensations converge. The space acquires conditions based on needs, manifests itself as a result of these (Rifkin J. 2010) and allows, as producers resulting from experience, to recognize the place where collective development takes actions. In this article, space and place go hand in hand, being the commitment that defines the experience in geographical terms.

The following paragraphs are intended to go the one way (Piglia G. 2015) towards the understanding of democracy in a century where human values seek to be equated with spiritual transcendence and where feelings are active emotions that play in the community. Spaces where you can recognize your own and others questioners within a possible spectrum; where both parties are heard, disseminated without appropriation and linked as options. Is it possible to recognize the truth of the other as your own? Can the citizen of the XXI century observe relating fundamental values such as solidarity, honesty and listening, and define them as progressive actions for the development of society?
\end{abstract}

Keywords: citizen, democracy, empathy, space, solidarity, values.

Entre paredes de adobe, en tiendas de carpa, descansan los cazadores y los armadores de trampas después de su faena diaria. La ciudad duerme, y el campo duerme. Los vivos duermen en su tiempo, y los muertos en su tiempo. El marido viejo duerme junto a su esposa, y el marido joven junto a su esposa.

Todos se inclinan hacia mí, y yo me inclino hacia ellos. Y tal como es, siendo uno de ellos, más o menos soy yo. Y de ellos, de cada uno y de todos, yo tejo el canto de mí mismo.

Un canto a mí mismo $15^{\circ}$ (Whitman W. 1892).

\section{Democracia}

La democracia se entiende como algo bueno, aunque universalmente su recorrido no ha sido tal. Muchos de sus defensores y detractores insisten en que es difícil encontrar ejemplos de democracia real. En este siglo XXI claramente se encuentran aproximaciones pero, a menudo el «gobierno del pueblo» está subordinado al gobierno de un sector particular de dicho pueblo, excluyendo a sectores minoritarios y siendo una fachada a favor del poder de los intereses económicos creados. (Krznaric R. 2014).

En la burbuja regional que envuelve la isla de La Española, en específico la República Dominicana, la democracia suele equipararse con libertad. Sin embargo la capacidad de elección viene dando claros indicios parciales, basados en la visión de un grupo social y fomentados 
por altos medios de publicidad constante, dígase Instagram y Facebook. En estas plataformas la inmediatez es la forma; en ellas las acciones de ejemplos de activismo, socialismo y humanidad enmarcan conceptos globales a una escala regional.

En palabras de Siri Hustvedt «...estoy convencida de que asistimos a la política de la humillación» (The Guardian, 2018) y es que, la democracia, según la etimología griega, viene del pueblo demos y del poder kratos. En la definición de estas dos palabras se puede comprender que el poder de decisión y de mandar está en el pueblo que elige democráticamente; pero ¿Cómo elegir democráticamente cuando se vive en una sociedad donde la mentira no es un problema y donde a verdad es subjetiva? ¿Cómo desarrollar cuestionamientos democráticos cuando el algoritmo se ve parcializado por el número de likes? ¿Cómo se puede ser un activista democrático en el siglo XXI cuando una foto vale más que la acción per se?

Enmarcando el siguiente párrafo en una obra de teatro: si se le da un cuerpo a la democracia y este se cruza con la empatía, el resonar entre miradas sería la única alegoría. Y es que la empatía está en el corazón de la racionalidad real y va a la raíz de los valores, que son la base del sentido de la justicia. La empatía es la razón por la que se tienen los principios de libertad, equidad y verdad, que son componentes necesarios de la justicia democrática.

Es importante resaltar la capacidad de escuchar, reconociendo que es posible la diversidad de pensamientos basados en reflexiones individuales. Se puede tener diferentes opiniones y principios. La diversidad y la igualdad tienen su origen en el reconocimiento de que todas las personas deben ser tratadas con respeto, independientemente de donde provengan.

La perspectiva del «otro» nunca puede ser tan cognoscible como la nuestra. La perspectiva está moldeada por las experiencias y deseos de un individuo, y las comparaciones son inevitablemente con uno mismo: con un sistema de creencias y un marco de referencia que ha sido moldeado por una serie de factores usualmente geográficos (Levinas E. 2015).

La democracia en sí es una forma de ser en particular, una forma de estar con los demás. Tiene mucho que ver en la aproximación con los semejantes. «¿Los respetas? ¿Reconoces su dignidad? ¿Puedes identificar tu interés con el de ellos?» (Whitman W. 1992).

\section{Empatía}

Según Jeremy Ruskin, civilizar es igual a empatizar. El autor utiliza el término para relacionar la sensibilidad y concientización de la naturaleza empática; bien dice que «la civilización es completa en su significado gracias al desarrollo de la empatía a lo largo del tiempo».

Es por ello que, sin lugar a dudas, se puede cultivar la empatía a lo largo de la vida y usarla como una fuerza radical para la transformación social.

En un estudio realizado por el filósofo Roman Krznaric, se explica que el gran revuelo acerca de la empatía proviene de un cambio revolucionario en la ciencia de cómo entendemos la naturaleza humana. La vieja visión de que el ser humano es esencialmente una criatura egoísta está siendo empujada firmemente a un lado por la evidencia de que también es un resultado continuo del homo empathicus, el cual está conectado por la empatía, la cooperación social y la ayuda mutua (Krznaric R. 2014).

Nunca entiendes realmente a otra persona hasta que consideras las cosas

desde su punto de vista, hasta que te metes dentro de su piel y caminas en ella.

(Lee H. 1988).

Dándole contexto al término empatía; este es argumentado por muchos críticos ya que existe un problema en el hecho de que Darwin usó el término simpatía para describir los fundamentos evolutivos del sentido moral. Sin embargo, dado que la palabra empatía no se inventaría en 
inglés hasta principios del siglo $\mathrm{XX}$, es el significado con el que Darwin usa la palabra que en última instancia importa más que la palabra en sí. La evolución de la «simpatía darwiniana» hacia la empatía que se conoce actualmente, no se reflejó hasta después de la Segunda Guerra Mundial (Darwin, C.R. 1871).

Edward Titchener, estudiante del filósofo y psicólogo alemán, es a quién se le atribuye la primera traducción del término Einfühlung como empatía en 1908, y lo discutió con mayor detalle en unas conferencias realizadas sobre la Psicología Experimental de los Procesos del Pensamiento en 1909 (Titchener E.B. 1909).

Sin embargo, el uso más antiguo conocido de empatía en inglés proviene de un artículo de 1895 en The Philosophical Review por Lawrence Hinman, refiriéndose a un escrito de Kurd Lasswitz titulado Ueber psychophyische Energie und ihre Factoren, sobre la energía psicofísica y sus factores (Johnson E. 2017); explicando que la energía psicofísica es definida como la relación de toda la energía en cualquier cambio del órgano central con la intensidad. En palabras llanas, la energía cambia en torno a la intensidad y ésta puede deberse al reconocimiento hábitat-cional de donde éste se haya generado.

En dicho artículo Lasswitz (1895) explica la empatía como una cantidad física, una función cerebral fisiológica y como una relación de toda la energía en cualquier cambio del órgano central efectuado con intensidad (Johnson E. 2017). Es decir, que la empatía se puede sentir. Es una acción con reflejos físicos generados de manera consciente.

Dándo contexto a la empatía, se han encontrado estudios donde narran cómo la relación empática está vinculada con la historia de la civilización. Esto puede ser explicado de acuerdo a cinco ramas de estudio (Rifkin J. 2010):

1. Biología: El hecho empático se presencia sintiendo, no pensando. Es un acto innato. Puede que este concepto esté basado en los principios de Lasswitz explicados anteriormente.
2. Pedagogía: Se refuerza la inteligencia emocional, el carácter y el desarrollo de ideas críticas. Se enfatiza la experiencia de aprendizaje en colaboración.

3. Derecho: Más que sentencia, busca crear consciencia en términos como verdad, compasión, perdón, reflexión e integración social.

4. Economía: Concepto win-win. Dígase de compartir riesgos y colaborar.

5. Medioambiente: Desorden en masa empática, conceptos de entropía y reflejos de grandes gastos de energía.

Imaginar la sociedad dominicana actual dentro de estos principios parecería tan radical que incluso es difícil recrearlo mentalmente. La empatía es simplemente el hecho de comprender y experimentar indirectamente la experiencia de otra persona. Sin embargo, reconocer acciones basadas en el bien común como resultado de un conocimiento innato no suele ser la primera reacción.

Conscientemente el ser humano puede experimentar empatía y egoísmo a la vez.

¿Puede entonces la empatía ser el motor oculto de la historia humana?

\section{Espacio}

Más que resaltar el espacio en su definición y lo que conlleva, este artículo busca representar la esperanza que habita dentro de la experiencia de una democracia empática. Sin duda hay un destino que va más allá de nuestro espacio y de la supervivencia como especie.

La autenticidad de lo que he descubierto sobre mí se refuerza porque he visto reafirmado algo de mí en ti y de ti en mí.

(Kwok-Bun C. 2012).

Espacialmente, en los territorios cotidianos, la mayoría de argumentos se basan en una falsa dicotomía entre empatía y razón.

La razón por la que se entiende que todas las personas deben ser tratadas por igual, es 
porque la empatía abre la preocupación moral por grupos sociales desatendidos o marginados y esto repercute luego dentro los derechos y las leyes (Lakoff G. 1980).

\section{Progresión colectiva}

Creando una analogía de todos los conceptos usados anteriormente, se puede decir que el espacio se hace en torno a la respuesta colectiva. La realidad es que en colectivo estamos cableados para sentir empatía, es parte de nuestra naturaleza y es la base material y física que nos permite ser seres sociales.

La vida cotidiana está ciertamente llena de sufrimiento, estrés, injusticias, golpes bajos; pero en lo esencial se contrabalancea positivamente gracias a pequeños actos de gentileza y generosidad.

La compasión y el consuelo mutuos están en todo momento creando la benevolencia, tejiendo el vínculo social.

(Rifkin J. 2010).

Puede que resolver la contradicción entre empatía y democracia sea el reto dentro de la evolución como especie humana.

\section{Referencias}

Austin, J.L. (1975). How to Do Things with Words: Second Edition. Harvard University Press.

Darwin, C.R. (1871). The Descent of Man, and Selection in Relation to Sex. John Murray.

Didion, J. (2014). On Self- Respect: Joan Didion's 1961 Essay from the Pages of Vogue. Vogue Magazine. https: \\ vogue.com $\backslash$ articleljoan-didion-self-respect-essay-1961

Johnson, E.M. (2017). Sympathy, Empathy, and the Evolution of Darwin's Moral Sense. University of British Columbia Press.

Kohler, W. (1917). Intelligenzprüfungen an Anthropoiden. Royal Prussian Society of Sciences.

Krznaric, R. (2015). Empathy: Why It Matters, and How to Get It. Perigee Books.

\section{Conclusión}

Se puede reflexionar ante el hecho de que si la democracia es la expresión misma del pueblo donde se busca el bienestar y el bien común, ¿cómo y dónde se une la razón colectiva con el sentimiento humano? ¿Hasta qué punto el sufrimiento del otro es parte del ejercicio democrático?

La empatía es sin duda un acto que ennoblece y reconforta. Está cargada de muchísima dignidad humana, no solo en su definición también en su acción. No siente ni un ápice de revuelo individual que no tenga como fin el bien colectivo.

En la sociedad actual, la relación entre el ser y los demás repercute en el conjunto. Por eso, al adquirir una profunda sensación de identidad se puede generar empatía, permitiendo explorar el misterio de la conciencia y descubrir nuevos ámbitos de significado. Ser empático brinda un propósito al individuo en su colectivo, en su espacio y en el misterio interior que proyectamos.

Dicho misterio es llamado empatía imaginativa (Didion J. 1961), una prueba de la voluntad de ser. La liberación de las expectativas de los demás es donde reside el gran poder singular del respeto por uno mismo. Uno no se escapa para encontrarse a sí mismo y no encontrar a nadie en casa... uno es singular gracias al colectivo y viceversa; uno es realmente democrático gracias a la comprensión de la empatía.

Kwok-Bun, C. (2012). Cultural Hybridity: Contradictions and Dilemmas. Routledge.

Lakoff, G. (1989). No pienses como un elefante. Chelsea Green Publishing Co.

Lakoff, G. (2003). Metáforas de la vida cotidiana. University of Chicago Press.

Lee, H. (1988). How To Kill A Mockingbird. Grand Central Publishing.

Levinas, M. (1961)., Ética e Infinito. Antonio Machado.

Morrell, M.E. (2010). Empathy and Democracy: Feeling, Thinking, and Deliberation. The Pennsylvania State University Press.

Rifkin, J. (2009). La Civilización Empática. Paidós Estado y Sociedad. 
Titchener, E. (1909). Lectures on the Experimental Psychology of the Thought-Process. The MacMillan Company.

Viejó Bautista, M.J. (2014). La democracia política, social y económica. Universidad de Sevilla.
Whitman, W. (1855). Leaves of Grass. New York Review Of Books.

Whitman, W. (2013). Perspectivas democráticas y otros escritos. Capitan Swing.

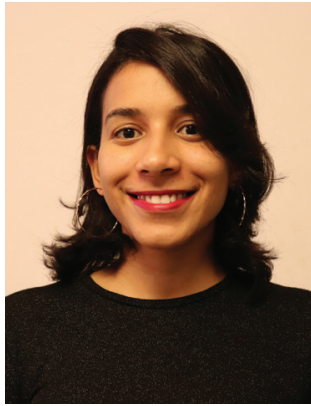

Natasha Amelia Abad Betances

Arquitecta egresada de la Universidad Iberoamericana (UNIBE). Es coordinadora de publicaciones de la Facultad de Arquitectura y Artes de la Universidad Nacional Pedro Henríquez Ureña (UNPHU). Ha sido Monitora de Filosofías Urbanas y es asesora de Proyectos de Grado en UNIBE. Actualmente está culminando su Máster en Diseño Arquitectónico, especialidad Diseño de Interiores, de la PUCMM y la Universidad de la Coruña. Ejerce su práctica profesional desde su firma $\mathrm{AB}$ espacios. 